\title{
Corrosion Behavior of AISI 1045 Carbon Steel in Metalworking Fluids Containing Pseudomonas xiamenensis
}

Qinghong Li ${ }^{1,3}$, Lihua Dong ${ }^{1}$, Yi Yang ${ }^{1}$, Zeqi Wu ${ }^{2}$, Hongling Zhu ${ }^{1}$, Yaohua Dong ${ }^{1}$, Yuanyuan Shen ${ }^{1}$, Li Zhang, ${ }^{1, *}$ Qingye $\mathrm{Lu}^{3, *}$

${ }^{1}$ College of Ocean Science and Engineering, Shanghai Maritime University, 1550 Haigang Avenue, Shanghai 201306, China

${ }^{2}$ Logistics Engineering College, Shanghai Maritime University, 1550 Haigang Avenue, Shanghai 201306, China

${ }^{3}$ Department of Chemical and Petroleum Engineering, University of Calgary, 2500 University Drive, NW, Calgary T2N 1N4, Alberta, Canada

*E-mail: zhangli@shmtu.edu.cn; qingye.lu@ucalgary.ca

doi: $10.20964 / 2020.01 .60$

Received: 2 September 2019 / Accepted: 30 October 2019 / Published: 30 November 2019

Microbial contamination of aqueous metalworking fluids (MWFs) is of significant concern in metal process industries. In this study, a dominant Pseudomonas sp. strain (P. xiamenensis) was isolated from waste metalworking fluids (WMWFs) and the biodegradation of model MWF was studied under the influence of $P$. xiamenensis. Results showed that nitric additives in MWF were severely degraded by bacteria, leading to a significant increase in the turbidity of the MWF. The occurrence of microbially influenced corrosion of AISI 1045 carbon steel in MWF containing P. xiamenensis, was proven by morphological analysis and electrochemical characterization. The corrosion rate of the metal in MWF in the presence of bacteria was three-fold greater than in the absence of bacteria. Electrochemical results and surface analysis elucidated that the additive film was decomposed by $P$. xaimenensis adhered to the steel surface and a biofilm, which was controlled by diffusion replacing the additive film. The biofilm was reinforced by the reaction of metabolites and $\mathrm{Ca}^{2+}$ and seriously localized corrosion behavior was observed in carbon steel immersed in the bio-contaminated MWF due to the microbial influence.

Keywords: metalworking fluid; biodegradation; AISI 1045 carbon steel; microbially influenced corrosion; electrochemistry

\section{$\underline{\text { FULL TEXT }}$}

(C) 2020 The Authors. Published by ESG (www.electrochemsci.org). This article is an open access article distributed under the terms and conditions of the Creative Commons Attribution license (http://creativecommons.org/licenses/by/4.0/). 